\title{
The gestural repertoire of the wild chimpanzee
}

\author{
Catherine Hobaiter · Richard W. Byrne
}

Received: 18 December 2010/Revised: 12 April 2011/Accepted: 14 April 2011

(C) Springer-Verlag 2011

\begin{abstract}
Great ape gestural communication is known to be intentional, elaborate and flexible; yet there is controversy over the best interpretation of the system and how gestures are acquired, perhaps because most studies have been made in restricted, captive settings. Here, we report the first systematic analysis of gesture in a population of wild chimpanzees. Over 266 days of observation, we recorded 4,397 cases of intentional gesture use in the Sonso community, Budongo, Uganda. We describe 66 distinct gesture types: this estimate appears close to asymptote, and the Sonso repertoire includes most gestures described informally at other sites. Differences in repertoire were noted between individuals and age classes, but in both cases, the measured repertoire size was predicted by the time subjects were observed gesturing. No idiosyncratic usages were found, i.e. no gesture type was used only by one individual. No support was found for the idea that gestures are acquired by 'ontogenetic ritualization' from originally effective actions; moreover, in detailed analyses of two gestures, action elements composing the gestures did not closely match those of the presumed original actions. Rather, chimpanzee gestures are species-typical; indeed, many are 'family-typical', because gesture types recorded in gorillas, orangutans and chimpanzee overlap extensively, with 24 gestures recorded in all three genera. Nevertheless, chimpanzee gestures are used flexibly across a range of contexts and show clear adjustment to audience (e.g. silent gestures for attentive targets, contact gestures
\end{abstract}

\footnotetext{
C. Hobaiter · R. W. Byrne ( $₫)$

Centre for Social Learning and Cognitive Evolution and Scottish

Primate Research Group, School of Psychology,

University of St Andrews, St Andrews,

Fife KY16 9JP, Scotland, UK

e-mail: rwb@st-andrews.ac.uk
}

for inattentive ones). Such highly intentional use of a species-typical repertoire raises intriguing questions for the evolution of advanced communication.

Keywords Communication - Pan - Intentional gesture · Ontogenetic ritualization $\cdot$ Species-typical $\cdot$ Family-typical

\section{Introduction}

It is a truth universally acknowledged that the greatest cognitive difference between humans and other animals lies in the use of language; thus, it is no surprise that vigorous research attention has been paid to communication among primates. Primate vocalizations were for many years the main target of study: human speech uses the vocal-auditory channel, and the development of technology allowed sophisticated sound analysis and playback to be applied. Extensive evidence of functionally referential calls, including some signs of meaning changes when calls are combined, has rewarded this quest to understand the primate precursors of language (Arnold and Zuberbuhler 2006; 2008; Cheney and Seyfarth 1990b; Hauser et al. 2002; Seyfarth et al. 2005; Zuberbuhler 2002). It is now clear that primates hearing conspecific calls can and do extract a wide range of information from them; it is less certain, however, that callers intend to create specific effects on hearers (Rendall et al. 2009). As with many animal vocalizations, simple audience effects are found (Snowdon 1990), but evidence is very limited for callers going any further-for instance, paying attention to the state of attention of the target audience and tuning their communication accordingly, or taking account of an audience's degree of knowledge or ignorance (Cheney and Seyfarth 1990a, 1996; though see Laporte and Zuberbuhler 
2010; Taglialatela et al. 2003). Moreover, the most highly referential calls, in the functional sense, are to do with the restricted context of giving warning of predators (Cheney and Seyfarth 1985; Seyfarth et al. 1980; Zuberbuhler et al. 1999), making it difficult to establish the flexibility of calling in general. Non-human primate calls themselves appear biologically fixed, in their form and in the general class of message they can convey. Calls develop towards particular forms and meanings without specific environmental guidance, under a wide range of rearing conditions (e.g. even in human-reared individuals), although the range of stimuli eliciting them may narrow down during development after early over-generalization to inappropriate contexts (Seyfarth and Cheney 1986). Unlike humans, cetaceans and many birds, the non-human primates have no facility for regularly learning new vocalizations (Janik and Slater 1997, 2003).

Gestural communication in primates, especially the great apes, does not suffer from these potential limitations. Studies of great ape gestural communication have systematically found that gestures are used flexibly across a range of contexts, such that the same gesture may be used in many contexts and a single context may elicit several different gestures (Tomasello and Call 2007, pp. 8-9). Choice of gesture is adjusted for the specific target audience, so that, for instance, 'visual' gestures (i.e. gestures that create no sound when made) are used more for audiences already attending to the signaller (Tomasello and Call 2007, p. 10; Genty et al. 2009; Liebal et al. 2004b, 2006; Pika et al. 2003; Tanner and Byrne 1996). When their aims are not realized, chimpanzees persist with gestural attempts to communicate (Leavens and Hopkins 1998; Leavens et al. 2005). And when the apparent understanding of a (human) audience is experimentally varied, orangutans react accordingly: if the person seems to half understand, they increase the gesturing rate, whereas if they seem to misunderstand completely, the orangutan chooses different gestures altogether (Cartmill and Byrne 2007). Furthermore, great apes evidently can learn novel gestures, as shown by the work of 'ape language' projects. Several projects used the signs of American Sign Language, a human system with minimal similarity to the natural gestures of great apes; yet individuals of three great ape species (chimpanzee Pan troglodytes, gorilla Gorilla gorilla, orangutan, Pongo pygmaeus) acquired extensive repertoires (Gardner et al. 1989; Miles 1986; Patterson and Linden 1981). In at least one case, new gestures were learned from another ape without human intervention (Fouts et al. 1989). These indications of flexibility, intentional usage and acquisition of novel gestures by learning have encouraged new interest in theories that human language might have originated from gesture (Armstrong and Wilcox 2007; Corballis 2010; Rizzolatti and Arbib 1998;
Vauclair 2004): ideas that originated from the close association of brain areas to which damage causes apraxias and aphasisas (e.g. Hewes 1973).

Nevertheless, it remains controversial how great ape repertoires are acquired and how ape gesture systems work in communication. In pioneering studies, Tomasello and collaborators examined the Yerkes captive group of chimpanzees over a period of 9 years, recording a series of three cross-sectional "snapshots" of the individual and group repertoires (Tomasello et al. 1994, 1985, 1989). They reported large differences in the gestural repertoires of individuals within the group, between the repertoires of immature and mature individuals at any one time, and between the repertoires of different cohorts of immature individuals over time. Such high variability led the authors to state that it is 'unlikely that particular gestures are transmitted across generations genetically', and instead they concluded that the acquisition of most gestures was most 'easily explained by a direct conventionalization process', with any overlap in gestural repertoires the result of common action repertoires and situations from which the gestures were conventionalized (Tomasello et al. 1985). Subsequently, in captive studies of several great ape species, widespread idiosyncrasy in gesture has also been reported (Tanner and Byrne 1999, and papers in Call and Tomasello 2007a). Furthermore, when great ape gestures were compared between and within groups, the degree of repertoire sharing was similar and few cases of gestures specific to particular groups have ever been recorded, making acquisition by cultural learning unlikely to be a general explanation (Call and Tomasello 2007a; Genty et al. 2009).

The idea that gestures may be 'conventionalized' was first proposed by Plooij (1978), who suggested that infant chimpanzees progress from 'unintentionally eliciting' actions from their mothers to deliberately doing so, as they gain awareness of the social effects of their behaviour: he described how the characteristic posture that infants adopt when being tickled became, over time, used as a gesture to request a tickling session (Plooij 1979). Tomasello and colleagues developed this suggestion into a formal hypothesis, 'ontogenetic ritualization', to explain acquisition of the bulk of the gestural repertoire they had observed (Tomasello 1990; Tomasello and Call 2007; Tomasello et al. 1994).

In ontogenetic ritualization, an individual A originally performs a physically effective behaviour sequence to attain its goal of influencing individual $\mathrm{B}$; over the course of many dyadic interactions, B comes to anticipate A's likely forthcoming behaviour sequence on the basis of its initial stages or preliminary intention movements and so responds 'early'. In turn, A comes to rely on B's anticipation, henceforth producing only the initial stage or an 
intention movement towards its goal, at which point A's behaviour has become a gesture for B (Tomasello and Call 2007 , p. 6). For instance, over a series of interactions, a young chimpanzee's forceful taking of food from its mother might become ritualized into a gesture of begging, as a consequence of the mother's anticipation of the desired result, and the youngster's subsequent realization that it needs to enact only the start of the taking action to achieve the desired result. Any action can thus become ritualized into a gesture, provided it predicts the whole action sequence with sufficient accuracy to allow anticipation. In another dyad, where $\mathrm{C}$ has the goal of influencing D's behaviour in just the same way, a different gesture might become ritualized: the process of gesture acquisition by ritualization can operate upon any effective action sequence, and there are often several possible ways of achieving the same physical result. The consequence is that each dyad might come to use different gestures for the same purposes; thus, widespread idiosyncrasy is to be expected in gestural repertoires, even with the same social group. By the process of mutual conditioning within dyadic interactions, relatively arbitrary intention movements can become ritualized into communicative gestures. Because the conditioned actions are originally ones made purposefully, ritualized gestures will show characteristics of intentional usage. Importantly, however, learning is not based on understanding of A's desire by B: the conditioned response depends only on anticipating the coming actions of A. Thus, the ritualization process only occurs in one direction: if the gesture of begging has become ritualized in A's repertoire as a result of B's anticipatory responses, it does not mean that $\mathrm{B}$ also has the begging gesture available for use. That would require the same process of mutual conditioning to happen, but with roles reversed. The process of ontogenetic ritualization should therefore lead to gestural repertoires characterized by high levels of both idiosyncratic and 'one-way' gestures (gestures used by A to B but not vice versa), just as Tomasello and his collaborators reported.

The interpretation of intentional gestures of great apes as ontogenetically ritualized actions, however, suffers from several difficulties, both theoretical and empirical. Firstly, the definition of idiosyncrasy used by Tomasello and colleagues means that a gesture is considered idiosyncratic if found to be used by only a single individual within a single study period. So, for example, they class the gesture 'Headgrab' as idiosyncratic despite the fact that in 1983 it was recorded in Georgia's repertoire and in 1991 it was recorded in Rhett's repertoire (Tomasello et al. 1994). This approach risks miscategorizing as idiosyncratic any species-typical gestures only used occasionally, exaggerating the apparent variability in the data: a particular risk with short-term studies of small captive groups. Similarly vulnerable to this sampling size problem is the use of 'oneway' gestures as evidence for ritualization. In any communication system, some levels of one-way usage of signals will be found: asymmetries in age, power and relationship mean that complete symmetry cannot be expected. Yet exactly how much one-way gesture use would point to an origin in ontogenetic ritualization is unclear, and as with idiosyncrasy, the rate of one-way usage is liable to be overestimated in short-term captive studies of small groups. A final theoretical concern is that, for every individual to learn every gesture in its repertoire of intentional gestures by ritualization, it would seem necessary to have a great number of repeated interactions; especially when it is remembered that each gesture needs to be ritualized dyadically with every one of the individuals to whom it can be used effectively. In a small and stable group, as in many zoo exhibits, this might be feasible, but the problem rises exponentially with group size. For a large community of chimpanzees exploiting a natural environment by fission-fusion ranging, the hypothesis stretches credibility, even though not every individual may communicate gesturally with every other.

An empirical source of weakness is that all studies of intentional gesturing in great apes report some gestures that, from their physical form, cannot possibly result from the ritualization of intention movements (e.g. all those gestures that are made by drumming on hard surfaces, including the body of the gesturer or its target). Thus, a second kind of explanation becomes essential. Tomasello and colleagues describe these gestures as 'attention getters' and suggest that they function only to draw the recipient's attention to an accompanying signal, either an unlearned expression or posture or another meaningful gesture (Tomasello et al. 1989). Of course, many gestures will naturally involve conspicuous components and may serve to get attention, but Tomasello and colleagues use the term for an exclusive category of gesture, in which 'the meaning of an attention getter most often derives not from the signal itself or from the surrounding context but rather from some accompanying behaviour' (Tomasello and Call 2007, pp. 10-11). Acquisition of these gestures also requires a second kind of ritualization to that of intention movements: the form of attention getters is clearly not derived from ritualization, but their use to gain attention is thought to be discovered from experience, such as in play. However, studies that have looked specifically for cases where an attention-getting gesture is paired with another gesture that has a semantic message have failed to find evidence for this pattern (chimpanzees: Liebal et al. 2004a; gorillas: Genty et al. 2009; Genty and Byrne 2010). Moreover, in gorillas, Genty et al. (2009) specifically divided the repertoire into those gestures which might plausibly derive from ritualized intention movements, and those whose form implied that 
they derived from species-typical displays. They then compared flexibility across contexts and the degree of intentionality or audience sensitivity, finding no clear pattern of difference between the gesture sets. These authors also examined idiosyncrasy of gesture in gorillas, across three captive groups and one field study, but using a definition that required that only a single individual should use a gesture for it to be called idiosyncratic. The result was that, as more studies were analysed, those gestures that seemed idiosyncratic in one group turned out to be used elsewhere, eventually leaving only one fully idiosyncratic gesture-used selectively to a human caretaker.

None of these problems is necessarily fatal to the hypothesis, but they do raise serious concerns. These especially concern the parsimony of erecting a rather elaborate hypothesis on the basis of relatively brief studies of often artificially structured populations (e.g. the Yerkes group was, at one point, a human-devised one-male harem, a social combination unheard of in natural chimpanzee behaviour), all carried out in captivity where the range of biological and social contexts is necessarily limited and there is a risk of artefacts from human influence.

We suggest that progress is most likely to come now from a study of great ape gesture in the wild and report here the first study specifically of this topic, in chimpanzees. We examine the repertoire of the Sonso chimpanzee community at Budongo, Uganda, looking for clues that may help resolve the controversy over gesture ontogeny. We do not distinguish a specific category of 'attention getters' because of the doubts noted above, but do examine gestures separately whose form is, or is not, compatible with a ritualized origin from intention movements.

We take the appropriate null hypothesis to be that the natural gestural repertoire of the chimpanzee is a result of genetic canalization into physical forms and potential messages that are species-typical, because this is considered the normal case for the communicative signals of most species of animal. Accepting this conclusion would not imply that the development of gestures must be unaffected by social interactions; nor that the ultimate form and usage of gestures would be identical across individuals; nor would it suggest gesture use is reflex-like and inflexible, or insensitive to audience. However, the particular forms and usages of gesture that develop would be somewhat determined by the species' biology, under the normal range of adaptive circumstances during development. Thus, in general, we would expect to find much the same repertoire of gestures in any population of chimpanzees, used in generally similar ways. (Strictly, species typicality does not imply genetic canalization: consider the universality of clothes among humans, for a possible example. But in the case of animal signals, this seems the simplest explanation.) Because the communicative systems of most animals consist of species-typical signals and because at least some great ape gestures appear to be species-typical (e.g. a chimpanzee drum, or gorilla chest beat), we feel that the species-typical hypothesis provides a parsimonious null hypothesis for the ontogeny of gestural communication in great apes. Against this null hypothesis, we examine the proposed hypothesis that some gestures, acquired through ontogenetic ritualization, vary from other (species-typical) gestures in terms of gesture flexibility across contexts and the degree of sensitivity to the audience's state of attention. We also consider the extent of idiosyncratic and 'one-way' gesture usage in the community, high levels of which are predicted from ontogenetic ritualization. Specifically, we ask whether the physical form of possibly ritualized gestures might betray characteristic signs of the gestures' origin in mechanically effective gestures. Finding no support for the predictions of the ontogenetic ritualization hypothesis in these analyses, we explore the consequences of accepting the null hypothesis of species typicality of gestures: we compare the gestural repertoire of Sonso chimpanzees with that of other chimpanzee populations, and with gestural repertoires of other genera of non-human great ape.

\section{Methods}

Study site and subjects

The Budongo Conservation Field Station was established in 1990 in the Budongo Forest Reserve, which lies in the western Rift Valley in Uganda $\left(1^{\circ} 35^{\prime}-1^{\circ} 55^{\prime} \mathrm{N}, 31^{\circ} 18^{\prime}-\right.$ $\left.31^{\circ} 42^{\prime} \mathrm{E}\right)$ at a mean altitude of $1,050 \mathrm{~m}$. The $793-\mathrm{km}^{2}$ reserve includes $482 \mathrm{~km}^{2}$ of continuous medium-altitude semi-deciduous forest cover (Eggeling 1947). The forest within this site is predominantly secondary forest growth, due to regular logging until 1990, which frequently restricts ground visibility to less than $6 \mathrm{~m}$.

At the start of data collection in October 2007, the Sonso study community of chimpanzees consisted of 81 named individuals. Following Reynolds (2005), we defined age groups as follows: infants ( $0-4$ years), juveniles (5-9 years), sub-adults (m: 10-15 years, f: $10-14$ years) and adults (m: $16+$ years, f: $15+$ years). Using these categories, the initial group composition was 32 adults ( 7 males and 25 females), 16 sub-adults (10 males and 6 females), 15 juveniles (6 males and 9 females) and 18 infants ( 3 males and 15 females). Over the course of the 22-month study, there were 10 deaths or long-term disappearances, 6 immigrations and 5 births, leaving the final total at 82. A large number of the Sonso chimpanzees suffer from injuries caused by snare traps, left in the forest by bush-meat hunters from local villages; in some 
particularly severe cases, the tendons within the hand or foot are permanently severed causing partial or full paralysis. The limitations of individual chimpanzees were well known, and data from individuals unable to extend the fingers fully were discarded from the appropriate analyses.

\section{Procedure}

Observations were made on chimpanzees within the Sonso community during three field periods between October 2007 and August 2009 (October 2007-March 2008; June 2008-January 2009; May 2009-August 2009). Primary data were recorded between 7.30 am and $4.30 \mathrm{pm}$, on a schedule of 3 days on, 1 day off, 3 days on, 2 days off; some supplementary observations were made outside these times, using the same protocol. Casual observations outside these times were also used in the final analyses. Because members of the Budongo Conservation Field Station follow individuals of the habituated group daily, locating chimpanzees did not normally present difficulties; however, location of specific individuals could be problematic, particularly for peripheral group members that may not be seen for weeks or sometimes months. The combination of low visibility and varied levels of habituation among individuals limited opportunities to capture clear video footage of social interactions. We therefore used a focal behaviour sampling approach (Altmann 1974) and maintained a record of the frequency with which a particular individual was observed; where we could choose which of several social interactions to film, we targeted individuals previously sampled infrequently.

All social interactions that were judged to have any potential for gestural communication were recorded on miniDV tape using a Sony Handycam (DCR-HC-55). Essentially, this meant any circumstance where two or more chimpanzees were present and not occupied in a solitary activity, such as self-grooming or sleep. Previous studies have found the highest frequency and variety of intentional gesture use in great apes to be in the context of play (Genty et al. 2009; Tomasello et al. 1994), so where several social interactions were taking place, we gave recording preference to those involving play. (Solitary play was also recorded, when no social interactions were in progress.)

\section{Analysis}

Digital videotapes were transferred to an Apple MacbookPro computer and scanned to locate episodes that apparently involved gestural communication; these were edited into discrete clips using iMovie and labelled for analysis and categorization in a Filemaker Pro database.
Data were converted to means for each individual, to remove any effect of pseudo-replication from the use of focal behaviour sampling. Analyses were carried out in SPSS v11, with $\alpha=0.05$ required for significance. Means are given \pm standard deviation, throughout.

Data were all examined for appropriateness for parametric statistics, and where necessary, transformations applied and the data retested. Where no appropriate transformations were possible, non-parametric alternatives were used. All statistical tests were two-tailed.

\section{Defining gestures}

Gestures were defined as discrete, mechanically ineffective physical movements of the body observed during periods of intentional communication. These movements included movements of the whole body, limbs and head, but not facial expressions or static body postures. With contact gestures, it was sometimes difficult for an observer to distinguish whether an action was mechanically effective in achieving its aim or communicating a gestural request for it; in such cases, we erred on the side of caution.

We define intentional communication broadly, as communication deliberately targeted to a particular recipient, with the aim of influencing their behaviour in a specific way. Thus, where gesture use was accompanied by one or more of the following, we took it that the gestures were being used intentionally:

Audience checking: The signaller shows signs of being aware of the potential recipients and their state of attention, e.g. turning to look at the recipient before gesturing.

Response waiting: The signaller pauses at the end of the communication and maintains some visual contact.

Persistence: The production of further gestures, after response waiting and in the absence of a response that in other cases is taken as satisfactory. (In certain circumstances, such persistence might be impossible, for example where an adult carries an infant away; these cases are marked as unable to persist, rather than no persistence.)

Where a string of gestures, separated by less than $1 \mathrm{~s}$, was followed by response waiting, we attributed the intentional aspect to every one of the gestures within the string (see Analysis: Describing the structure of gestural communication, below). Insisting that each instance of gesture use must be within provably intentional communication is of course conservative; the procedure forced us to discard many cases that may have been intentional communication. However, where previous researchers have made a similar stipulation (Call and Tomasello 2007a; Genty et al. 2009), they have nonetheless found abundant gestures to analyse. 


\section{Measuring repertoires}

Captive studies usually distinguish between idiosyncratic gestures that form part of only one individual's repertoire and those that are used by more than one individual within a social group, forming the group repertoire. The community of chimpanzees at Budongo was much larger than any chimpanzee group yet studied in captivity, which gave us the opportunity for a finer classification. In particular, we considered the possibility that a gesture might be used within a matriline yet not generally within the social group. We therefore distinguished an intermediate level of usage, where gestures were used by several members of a matriline.

For categorization as part of an individual's repertoire, we required a gesture to be recorded used at least twice by that individual; idiosyncratic gestures were those only recorded in one individual's repertoire and never observed in any other individual. Note that this contrasts with the definition used by Tomasello and collaborators, who considered a gesture idiosyncratic if it was found in only one individual in a relatively short study period, even if it was known to be used by others in the group at other times (Tomasello et al. 1994). For categorization as part of a matrilineal repertoire, we required a gesture to be included in more than one individual's repertoire from the same maternal family line; 'matrisyncratic' gestures would be those only ever observed in individuals of a single matriline. Where a gesture was used by more than one individual, not in the same matriline, we classed it as part of the group repertoire. Note that it only takes one counterexample to disconfirm apparent cases of idiosyncrasy and 'matrisyncrasy'.

\section{Classifying gestures by modality}

We categorized gestures according to modality used. Visual, audible and tactile have often been used as categories in the past, but these terms make presumptions about the recipient. Thus, all gestures are visible, and it is the lack of any audible component that distinguishes some distal gestures from other, 'audible' ones; we prefer the term 'silent'. Similarly, we use the term 'contact' rather than tactile, in order to recognize the active intent of the action.

Classification of gestures as silent or audible was not always straightforward. In a dense forest environment, whether or not a gesture happens to make a noise may be a matter of circumstance. Shaking a sapling, for instance, might be intended as a visual display, but sometimes leaves rattle audibly; in the dry season, the quantity of dry leaves makes almost all movements audible. We classified gestures as audible only where they were made audible by their intrinsic features. However, we also noted whether a 'silent' gesture, or some element of the signaller's behaviour at the time of gesturing, made any noise, so that we could identify cases where the recipient was likely made aware of the signaller's presence, even though their intentional gesture was a silent one. Similarly, vocalization at the time of gesturing was recorded.

\section{Describing the structure of the gestural communication}

As with many forms of real-life communication, the use of gesture is not necessarily a straightforward matter of taking turns: gestures by two individuals may overlap in time, and each participant may gesture in a sequence that may or may not include pauses for response waiting. In order to describe this potential complexity, we broke down chimpanzee gesturing into discrete structural phases. Following Genty et al. (2009), we used a pause of $>1 \mathrm{~s}$ to delimit a single sequence of gestures made by the same individual. Where the cut and thrust of communication went back and forth between two individuals, both individuals were considered to be 'actively gesturing' throughout the clip, whereas, when a signaller gestured to an uncommunicative recipient, only the signaller was credited with being actively gesturing.

Each individual gesture was coded for: modality (Audible, Silent or Contact); situational context (Affiliation, Agonism, Boundary Patrol, Consortship, Feeding, Grooming, Resting, Sex including mating and inspections, Solitary Play, Social Play, Travelling or Unknown); recipient's state of attention (Attending: recipient has eye contact with the signaller or demonstrates clear tracking of the signaller's actions, by head movements which match and track the signallers own movements; In full view: recipient is in frontal view of the signaller, i.e. an $\operatorname{arc}$ of $25^{\circ}$ either side of the direction the signaller is facing; Partial view: recipient is in signaller's peripheral view, i.e. an $\operatorname{arc}$ of $90^{\circ}$ either side of the direction the signaller is facing, excluding the narrower zone of full view; Out of sight: recipient is not in a position to see any physical movement made by the signaller; Out of sight with body contact: as Out of sight, but recipient is in body contact with the signaller and therefore presumably aware of their presence). For sequences of gestures, we took it that all gestures in the sequence would concern the same goal and that any response was to all the gestures in the sequence (see Cartmill and Byrne 2010, for discussion). The following aspects were therefore coded identically for all gestures in a sequence: apparent goal (Acquire object/food, Affiliation, Attract Attention, Chase, Climb on self, Climb on other, Direct attention, Follow, Groom self, Groom other, Sexual attention, Move away, Move closer, Play start, Play continue, Play change, Pick up, Position, Recipient stay in same state, Stop behaviour, Other or Unknown); recipient's response (Gesture, Other action or None). 
To examine the possibility that gesture modality (i.e. silent, audible, contact) might be chosen with respect to the recipient's state of attention, we calculated the variations in choice of silent, audible or contact gestures, according to the attentional state of the audience. We examined only the first gesture in each sequence, and individuals with fewer than 5 gestures in each category were excluded from this analysis. For each individual, we first calculated the proportions of its entire gesture usage that involved silent, audible or contact gestures. Then, we selected from that individual's data two subsets: cases where the apparent target audience was attending (that is, making eye contact with the signaller or moving its head to track movement of the signaller) and cases where the signaller was out of view of the apparent target audience. For these subsets, we again calculated the proportion of gesture use that involved silent, audible and contact gestures. We then calculated the percentage deviation in the variation in use of each mode of gesture for each subset of audience attention state. Thus, if the proportion of silent gesture in the overall corpus was $\alpha$ and the proportion of silent gestures when eye contact had been made was $\beta$, the deviation would be $(\beta / \alpha-1) \times 100$. Deviations, which could be positive or negative, were used to indicate active adjustment towards the attentional state of the recipient.

\section{Distinguishing ontogenetically ritualized from species- typical gestures}

Ontogenetic ritualization requires that the physical form of the gesture be ritualized from the incipient movements of an effective action, in the course of dyadic interactions during individual ontogeny (Tomasello and Call 2007). We treated all gestures that could reasonably be described as the incipient movements of an effective action as 'potentially ritualized' (PR). A typical example is the beggingreach gesture, used to solicit food or other desirable objects, which might have become ritualized from the (originally effective) action of taking the object directly. In so doing, the reaching movement might often have been the first part of the action sequence, terminating in a mechanically effective grasp. Only where a gesture could not reasonably have originated in an intention movement, or the early part of a sequence of action that could have achieved the same goal, did we treat the gesture as 'species-typical' (ST). Note that this classification is asymmetric: whereas the form of ST gestures could not be derived from ritualization during ontogeny, by our definition, those we classed as PR gestures might in fact be part of the chimpanzee's natural repertoire and more properly classified ST.

If this classification is appropriate and even if not every one of our attributions is correct, then we would expect a characteristic difference in communicative attributes to emerge. Thus, gestures learned by ritualization during dyadic interactions, compared with speciestypical displays, might be expected to be used more flexibly, and more obviously used in a deliberate way under voluntary control. (Indeed, the stipulation of intentional use might have removed all species-typical displays.) We examined the data for evidence relevant to these predictions.

In addition, if a gesture has been ritualized from an originally effective action or an intention movement towards that action, it should sometimes retain a trace of its ontogeny in its physical form. In particular, we would expect consistency in the manner in which the movements of gesture and original action are performed: the direction of movement, the orientation of the hand and so forth. If, on the other hand, the identification between communicative gesture and its presumed pre-ritualization origin is spurious, we would expect no such consistency. In order to examine this prediction, we analysed the physical movements in which two PR gestures were conducted, comparing them with the actions from which they might have ritualized. These were the 'begging-reach' gesture, i.e. a 'reach' gesture given with the apparent goal of acquiring a desired object, compared with the 'take' action; and the 'position' gesture, used to indicate a desired position during grooming, compared with the 'position' action. We chose these gestures not only because they were sufficiently common in our corpus to allow analysis but also because they are particularly obvious candidates for explanation by ontogenetic ritualization.

Begging-reach gestures and actions of taking were described using three categories: palm orientation (Vertical, Up or Down), position of fingers (Curled or Extended) and the part of the hand presented first to the recipient (Front of fingers, Back of fingers, Wrist or Hand). Position gestures and actions of positioning were categorized according to the part of the hand used to perform the movement (Front of fingers, Back of finger, Palm, Knuckles or Back of Hand). Only individuals with four or more examples in each category were analysed.

\section{Inter-observer reliability}

We recruited an experienced coder of gorilla gestural communication to analyse independently a subset of 50 gestures from video on three aspects: Is the gesture directed to another individual? What is the attentional state of the recipient? And what is the gesture type? The procedure for coding these variables was one with which the coder was already familiar, although the possible values differed in places (e.g. the gesture type). A fairly high level of agreement was achieved on all three variables (Cohen's 
kappa: directedness $K=0.69$, attentional state of recipient $K=0.63$, gesture type $K=0.86$ ).

\section{Analysis}

For parametric statistics, all data were examined for skewness and homogeneity of variance, and where necessary, transformations were applied and all such cases are labelled in the "Results" section. Where no appropriate transformations were possible, non-parametric alternatives were used. For skewness, $Z$ values over 1.96 or under -1.96 were considered to be positively or negatively skewed. In the case of positive skew, a transformation of either $\sqrt{ }(x)$; or, where the data set include negative percentage values $\sqrt{ }(x+101)$, was applied. In the case of negative skew, we used the transformation: $\sqrt{ }\left(\left(x_{\max }\right.\right.$ $+1)-x$ ), where $x_{\max }=$ the highest value within the data set. Transformed data were then retested for skewness; if $Z$ values remained outside of the appropriate bounds for parametric statistics, non-parametric alternatives such as Kruskal-Wallis were used. Homogeneity of variance was evaluated with Levene's test. Where Levene's statistic showed the assumption of homogeneity was not applicable, an alternative test was used, such as $t$ test $_{\text {unequal variances }}$ or ANOVA Brown-Forsythe.

Where planned comparisons could be made, standard $t$ tests or their non-parametric equivalents were used, with Bonferroni correction if the number of planned comparisons equalled or exceeded the number of experimental conditions. In the case of unplanned, post hoc tests we used Tukey's HSD in the case of equal sample sizes or the equivalent Games-Howell test where sample sizes varied between conditions or where the requirement for homogeneity of variance was violated.

\section{Results}

During 266 days of observation, we recorded $111 \mathrm{~h}$ of chimpanzee behaviour that were considered to have the potential for gestural communication. Other researchers working with the same community kindly contributed a further $19 \mathrm{~h}$ of video, giving a total $120 \mathrm{~h}$ of footage. This produced a data set of 4,397 gestures (that is, instances of gesture use); many other potential gestures were excluded because they failed to meet one or more of the requirements for intentional use.

\section{Repertoire}

In total, we identified 115 different gesture types; however, many of these could be considered variations on a single type (for example grab 1-handed, grab-2-handed). Where there was no reason to think that these small structural differences had any communicative significance, we lumped categories to give an eventual set of 66 distinct gesture types (see Table 1), 5 of which were recorded less than 3 times during the study. Of the 66 gesture types, 29 (43.9\%) could plausibly be classed as potentially ritualized (PR), leaving 37 gestures that could only be understood as species-typical displays (ST). Examining the cumulative frequency of gesture types, as used by any member of the chimpanzee community, suggests that our assessment of the community repertoire approaches or has reached asymptote (Fig. 1); further observation is therefore unlikely to contribute many further gesture types.

Individual repertoire size varied considerably $(n=62$, range: $1-41$, mean $=10.0 \pm 8.9$ ). Age classes differed significantly from each other in the average size of repertoire (ANOVA Brown-Forsythe $F_{3,35.8}=4.62, P=0.008$; see Fig. 2). The juvenile age group evidenced the largest individual repertoires $(n=14$, range $1-35$, mean $=$ $15.14 \pm 11.89)$, followed by sub-adults $(n=17$, range $1-23$, mean $=9.76 \pm 7.54)$, infants $(n=14$, range: $1-23$, mean $=7.86 \pm 7.18)$ and finally adults with the smallest individual repertoires $(n=29$, range: $1-17$, mean $=$ $5.10 \pm 4.64)$. The difference between juvenile and adult repertoires was significant (post hoc Games-Howell: mean difference $=10.04, P=0.037$ ).

There are several reasons for thinking these measured repertoires underestimate the true sizes of individual gestural repertoires, however. Only the largest individual repertoire that of Night (female, 4 years old at start of data collection) appeared close to asymptote. Indeed, repertoire size was closely correlated with the active gesture time recorded for that individual (Pearson's correlation $r=0.94, n=68, P<0.0001$; active time gesturing, $n=$ 68 , range: $0.27-160.28 \mathrm{~min}$, mean $=29.67 \pm 36.34 \mathrm{~min}$; see Fig. 1). Moreover, if the criterion for repertoire membership were relaxed to include gestures used only once, estimated individual repertoire sizes would almost double $(1: 1.81 \pm 0.67)$. For age category differences, the size of the repertoire was similarly closely correlated with the amount of active gesture time recorded within the age group (using a fine division of age classes: $n=7$, Pearson's correlation $r=0.97, P<0.0001$; note also the large overlap in size of ranges, Fig. 2). Looking at it another way, the number of individuals in whose repertoire a gesture type was recorded was strongly correlated with the overall frequency of the gesture type (Pearson's correlation $r=0.89, n=66, P=0.0001)$. Thus, measured individual repertoires, and the significant variation between gesture types in how widely they were used, appear to be determined largely by sample sizes. 


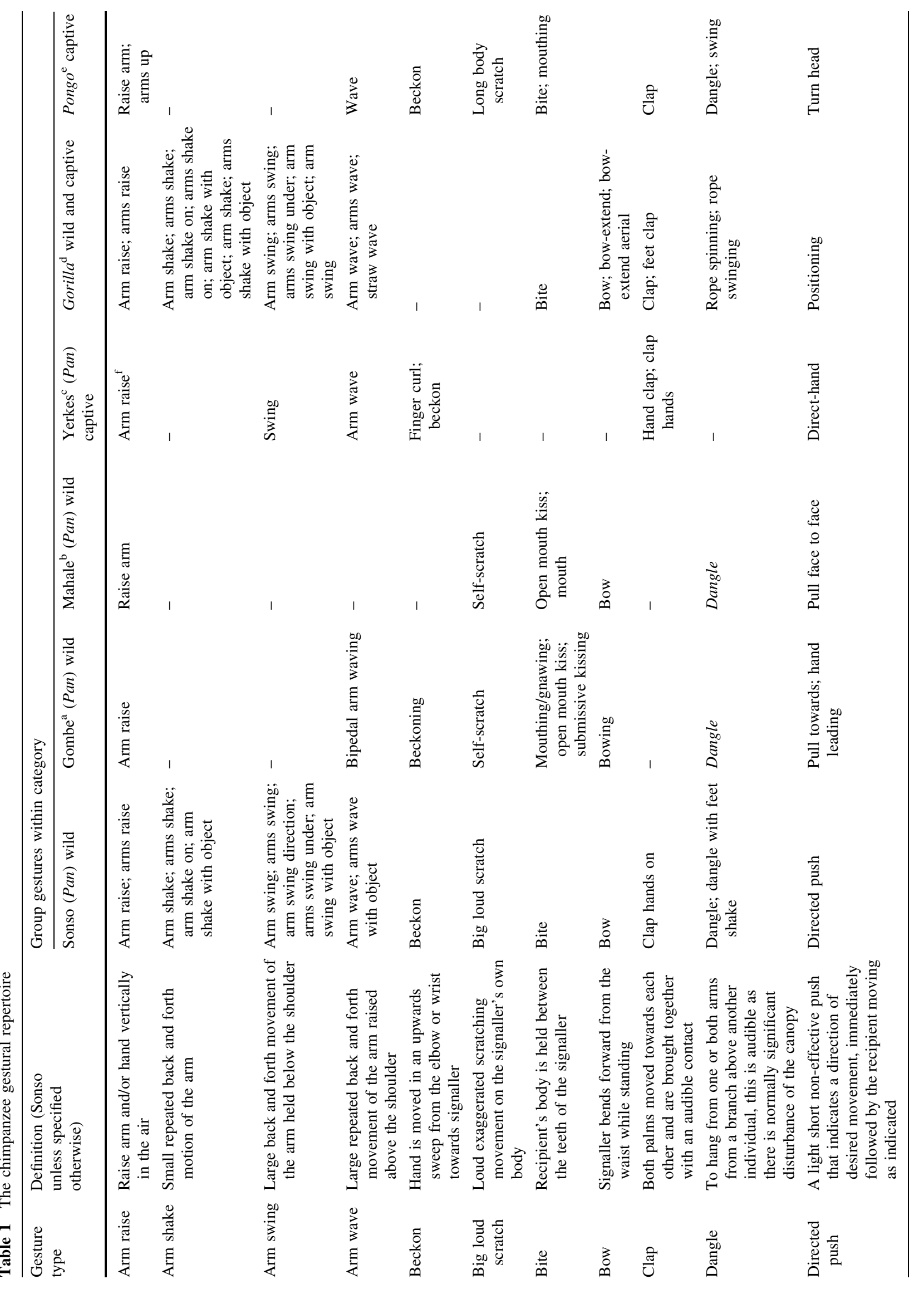




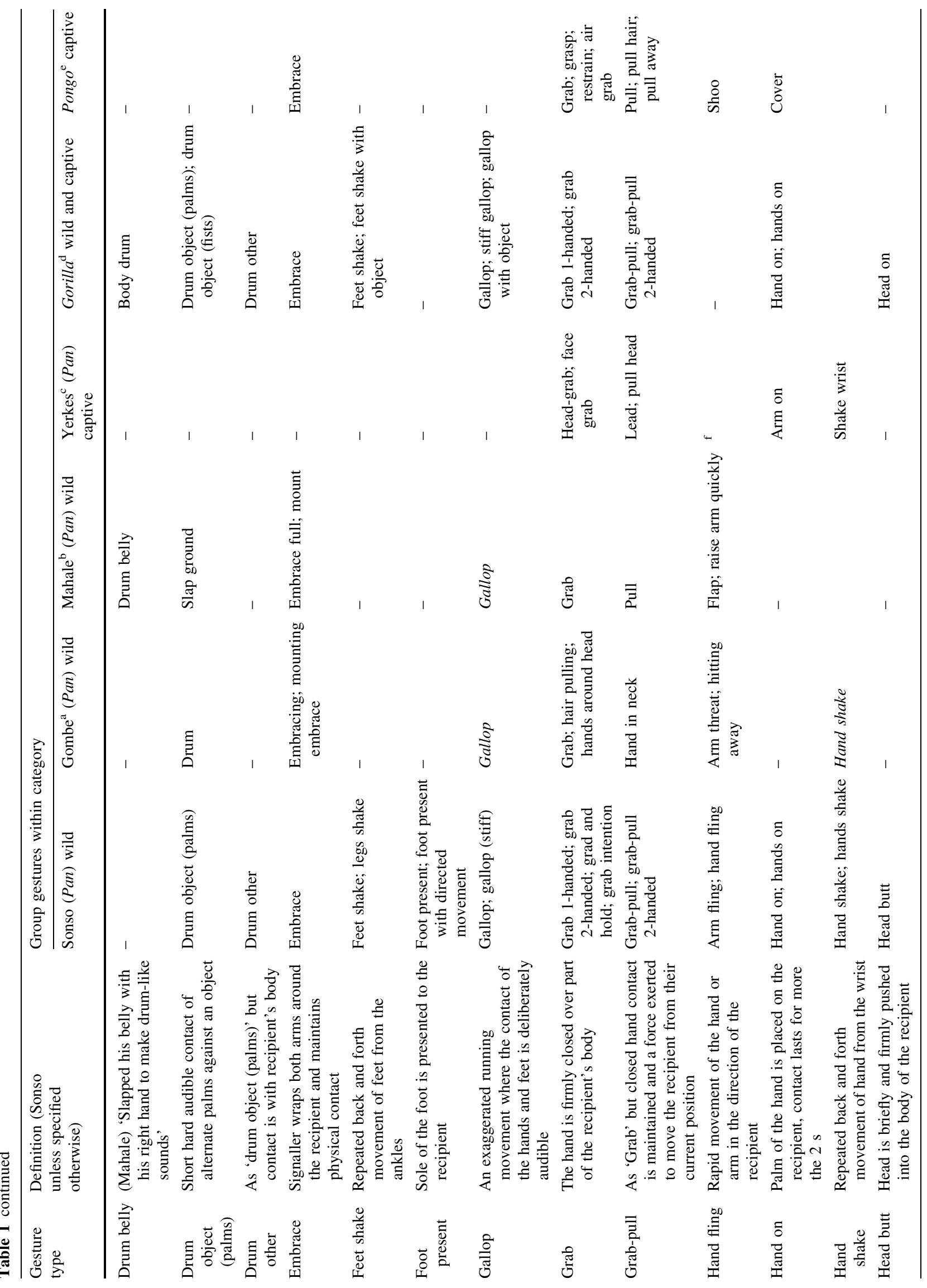




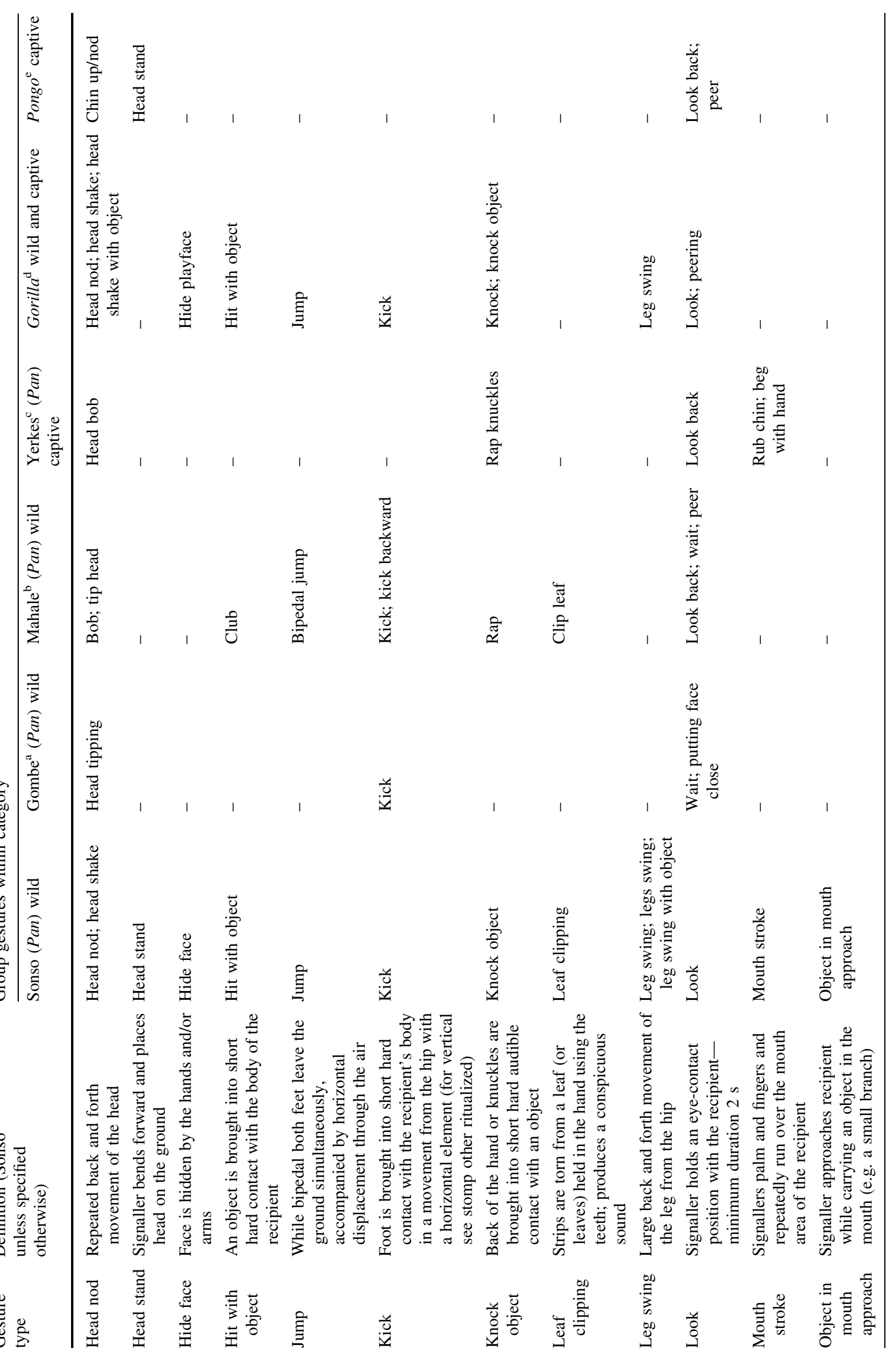




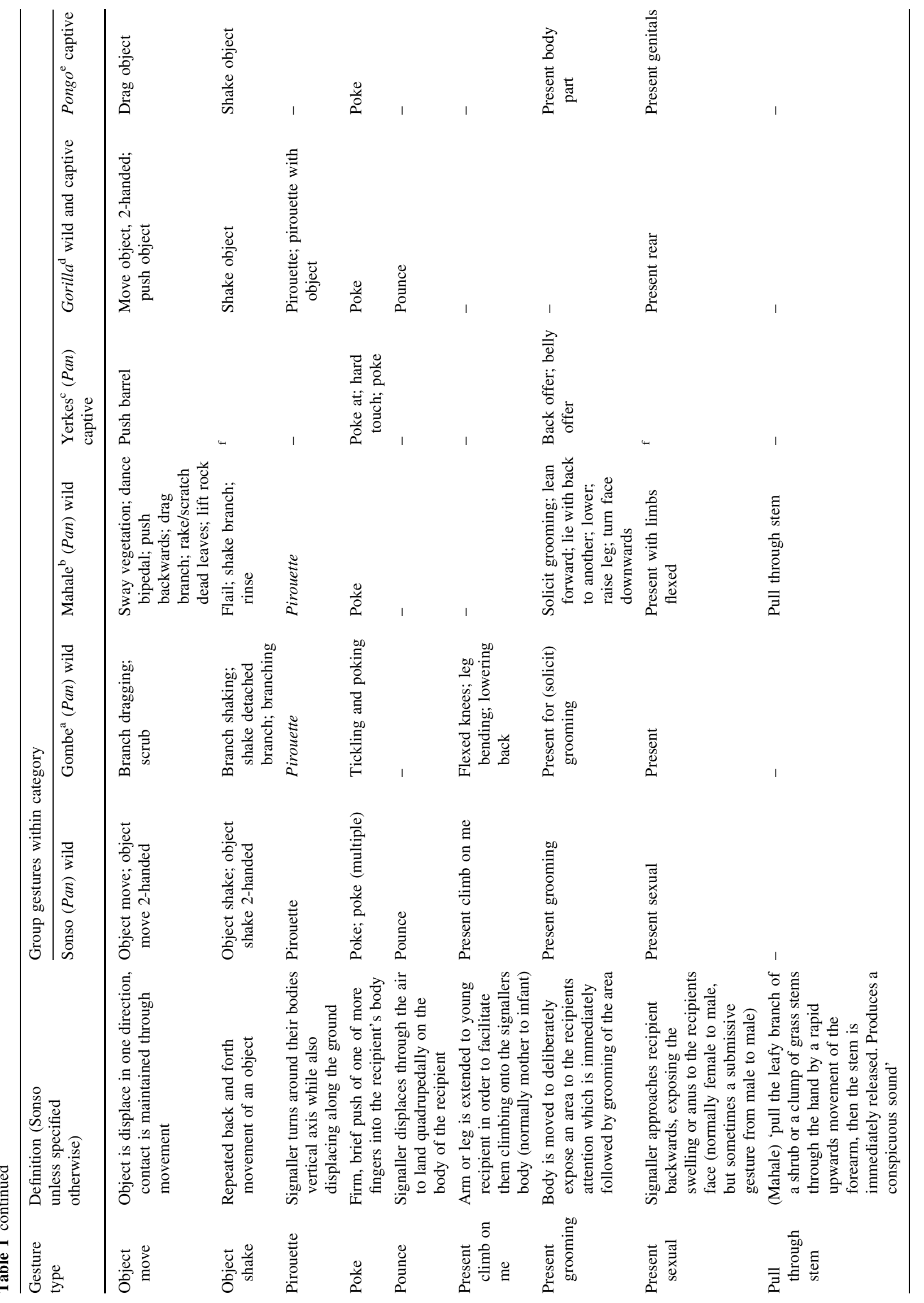




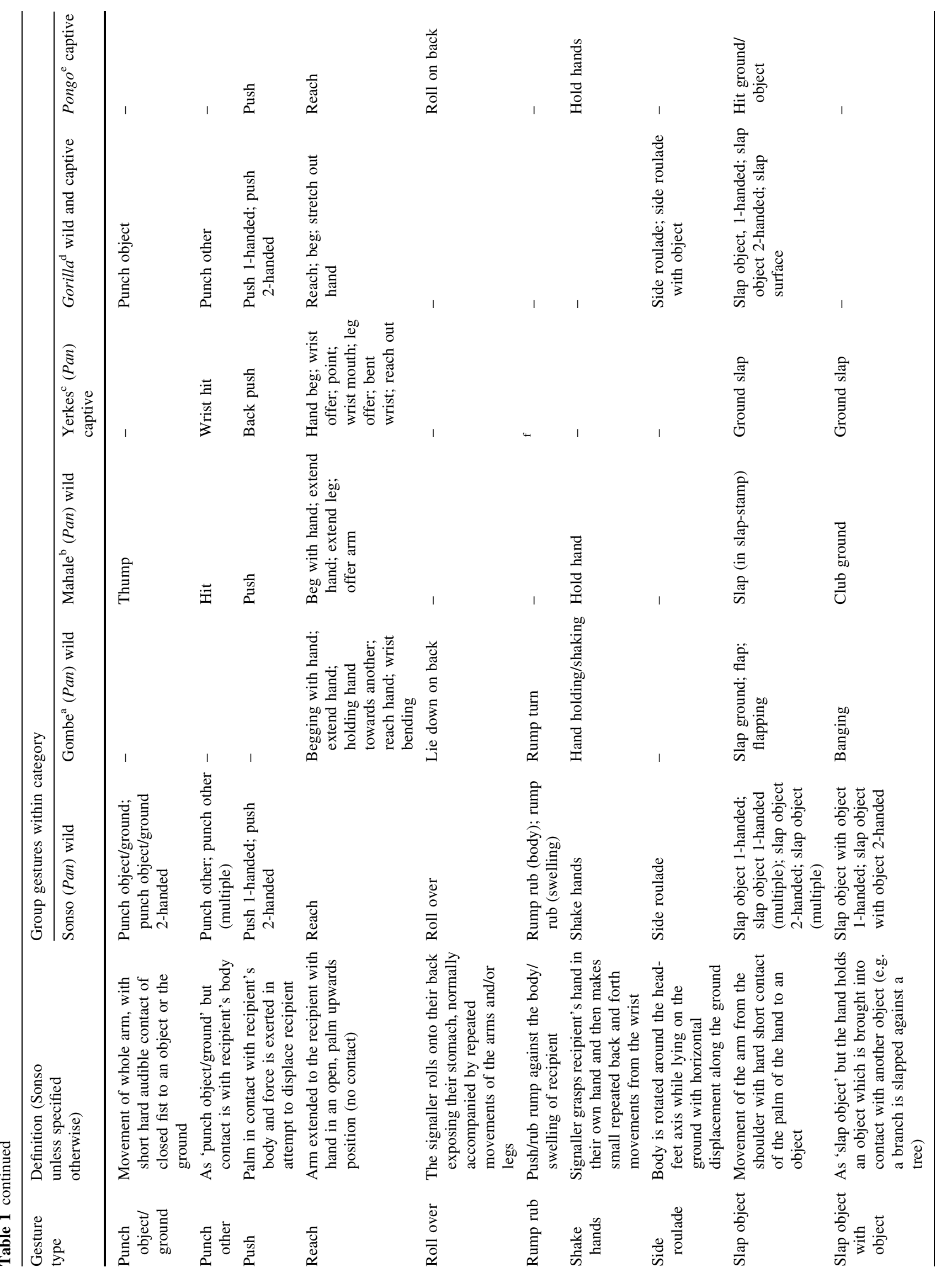




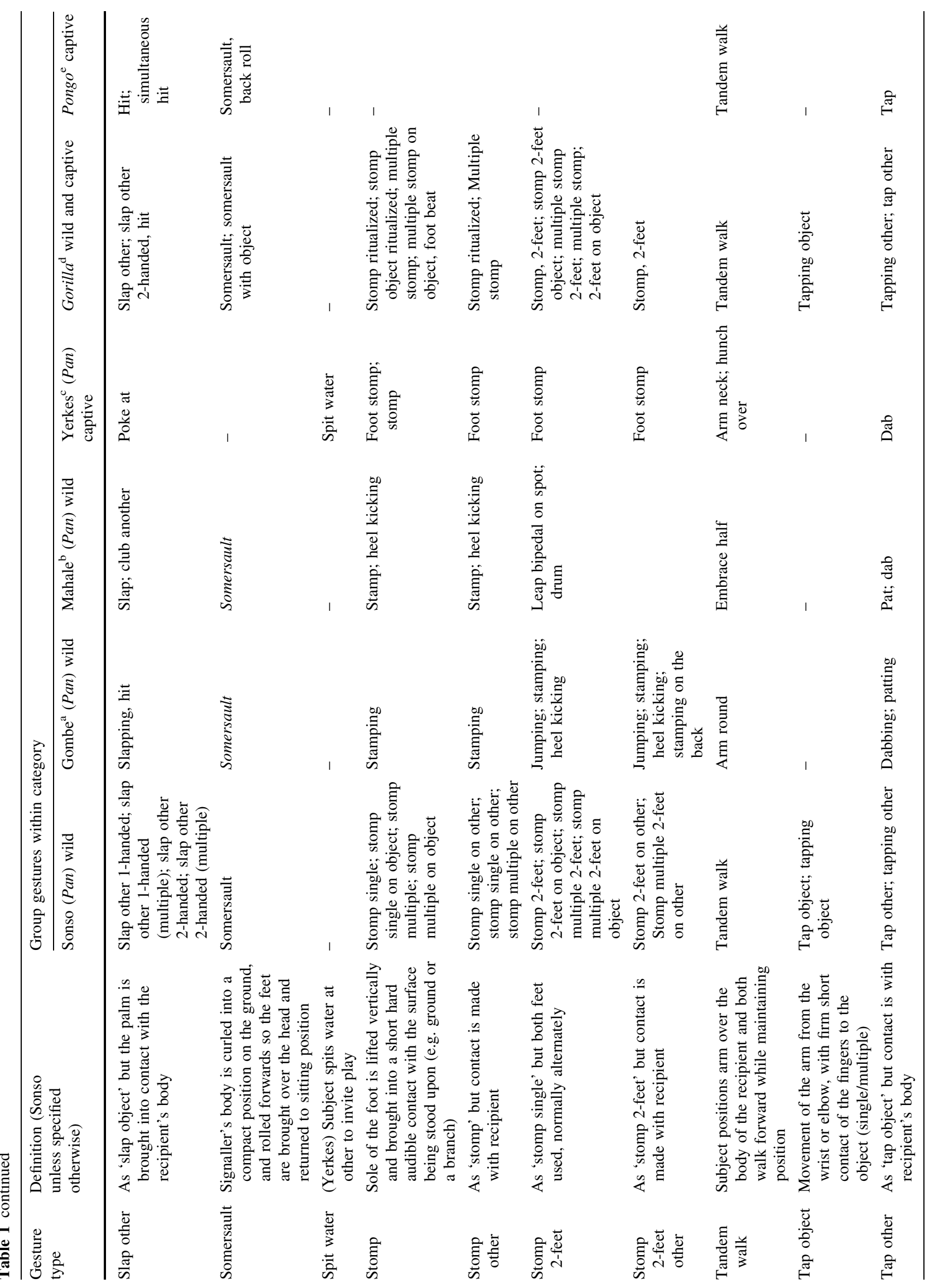




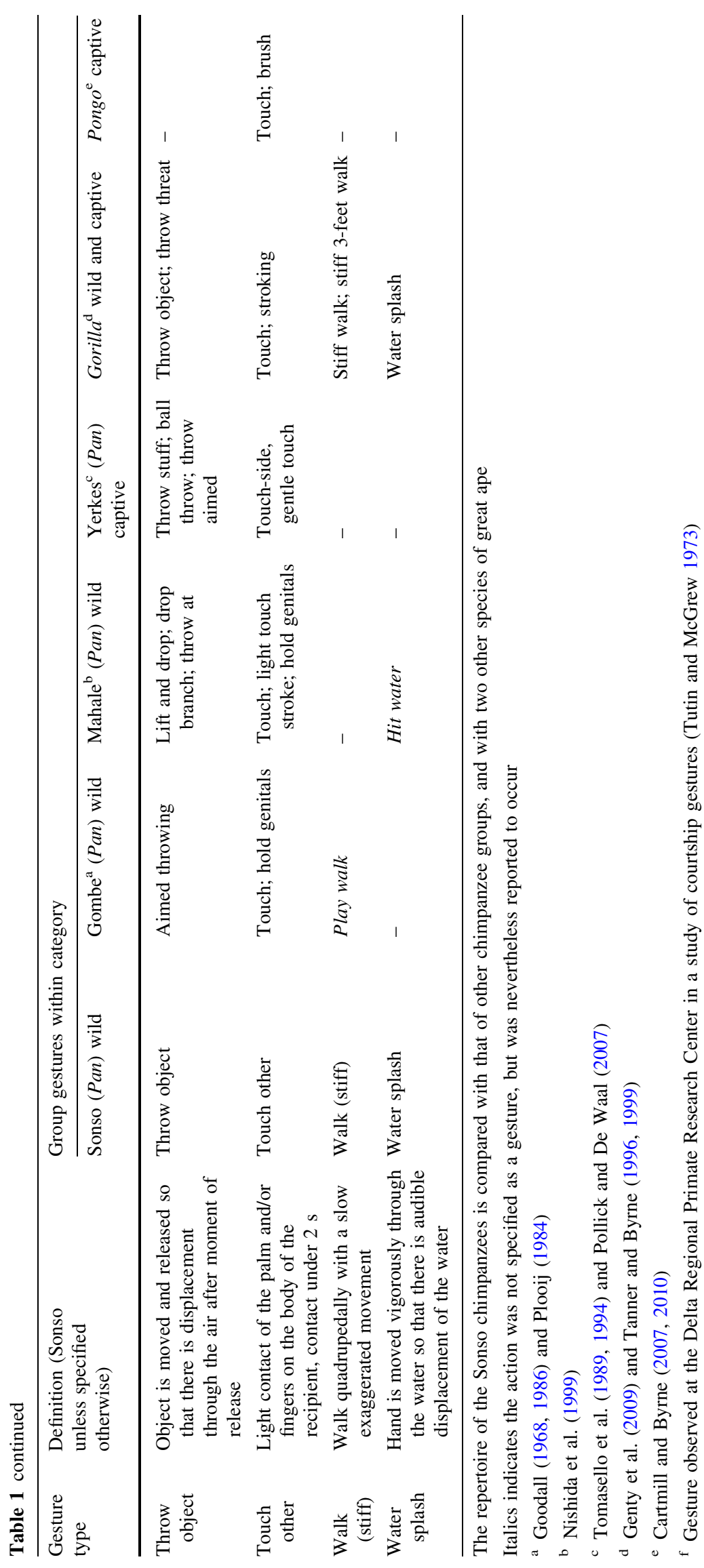




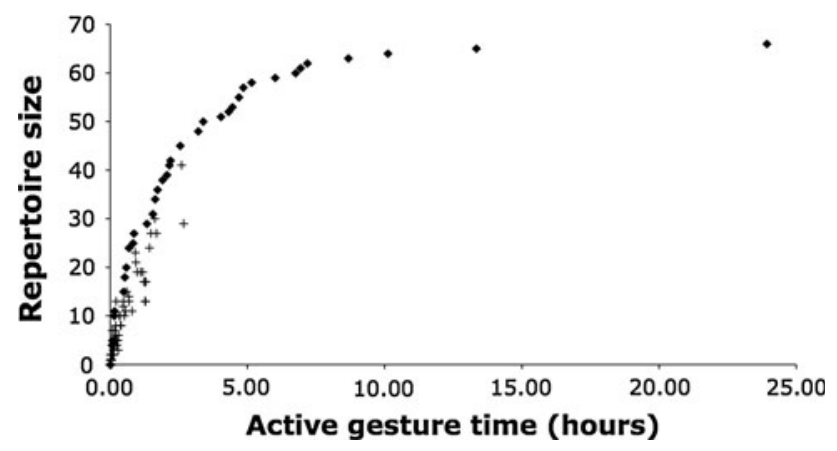

Fig. 1 Cumulative record of Sonso repertoire. The cumulative number of gesture types recorded is plotted against the 'active gesture time' for the Sonso community as a whole (solid diamonds). Asymptote appears to be reached at approximately $15 \mathrm{~h}$ of active gesture time, which corresponds to approximately 150 days of field observation time. In addition, on the same axes, the repertoire sizes of individuals are plotted, against active gesture time recorded during the study for each individual (crosses)

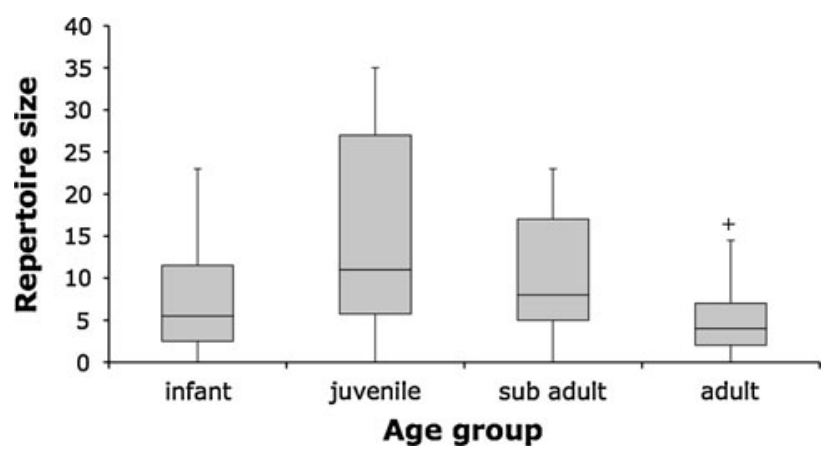

Fig. 2 Age distribution of chimpanzee repertoire size. Repertoires for each age class are given as box-plots, with mean, SD, range and outliers shown

Do potentially ritualized differ from other gestures in signs of intentional usage?

\section{Flexibility}

Following Call and Tomasello (2007a, b) and Genty et al. (2009), we used the range of situational contexts in which each gesture was recorded to estimate its flexibility. Both PR and ST gestures were produced in several contexts (Fig. 3). Although the spread was slightly higher for PR gestures (1-9) than for ST gestures (1-7), there was no significant difference in flexibility (gestures with 3 or more recorded examples: $n=94$, chi-square $\chi^{2}=13.76$, $d f=8, P=0.09$; see Fig. 3).

\section{Adjustment for audience}

As the attentional state of the audience was assessed for whole gesture sequences (i.e. a string of gestures separated by $<1 \mathrm{~s}$ ), we limited the data set for this analysis to

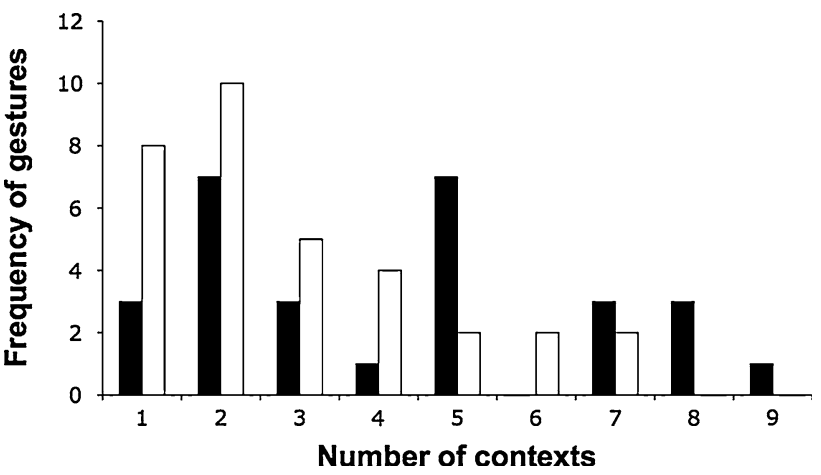

Fig. 3 Context specificity of gestures. The frequency of gesture types are plotted against the number of distinct situational contexts in which they were recorded. Black bars represent gestures whose form suggested that they might be potentially ritualized; white bars represent gestures whose form only allowed explanation as speciestypical

gestures used singly or as the first gesture in a sequence. This gave 3,410 gestures for analysis.

We first examined whether, for the gesture corpus as a whole, there was evidence that the audience's attentional state was taken into account. To show any such effect, we calculated the variations in choice of silent, audible or contact gestures, according to the attentional state of the audience (Fig. 4). The choice of different modalities of gesture varied significantly with the recipient's attention state $\left(n=225\right.$, ANOVA $\left.f_{5,219}=50.70, P<0.0001\right)$. Specifically, silent gesture use increased when the recipient was attending and decreased when they were out of sight (attending: $n=40$ mean $=14.5 \pm 37.0$; out of sight $n=35$ mean $=-64.9 \pm 36.7$; planned $t$ test $t=-9.31$, $d f=73, P<0.0001)$, and contact gesture use decreased when the recipient was attending and increased when they were out of sight (attending: $n=40$ mean $=-26.9 \pm$ 41.3; out of sight: $n=35$ mean $=49.7 \pm 67.5$; planned $t$ test $t=6.02, d f=73, P<0.0001)$. There was no variation in the use of audible gestures (attending: $n=40$ mean $=7.7 \pm 42.8$; out of sight: $n=35$ mean $=4.5 \pm$ 54.0; planned $t$ test $t=-0.29, d f=73, P=0.776$ ).

We then repeated this exercise for the use of PR and ST gestures separately, for each individual, and examined whether, for each modality, the variation in use differed significantly between PR and ST gestures, and between recipient attentional state. Thus, in this comparison, every individual provided a total of 12 measures of variation of use (PR, silent, attending; PR, silent, out of view; ST, silent, attending; ST, silent, out of view; etc.). Separate $2 \times 2$ between-subjects ANOVAs (or equivalent nonparametric alternative) were used to examine each mode of gesture (silent, audible, contact) for any effect of categorization, as PR or ST, or attention state on the variation in use of the mode of gesture. 


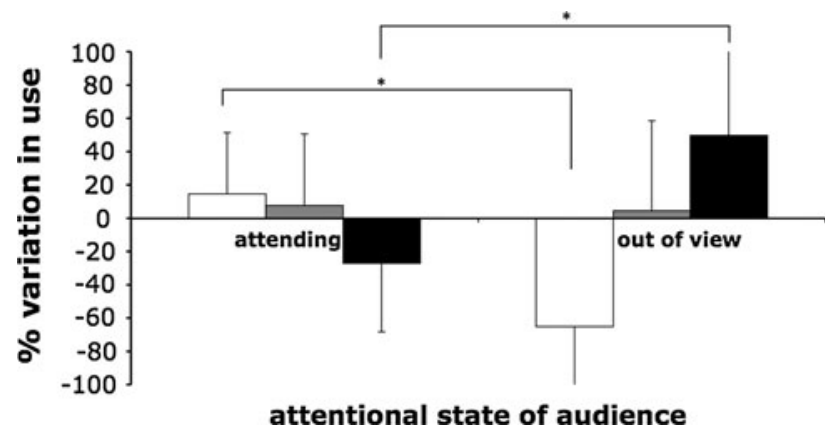

Fig. 4 Variation in use of gesture modes with recipient's state of attention. The deviations above and below the zero-line show changes, according to the target audience's state of attention (either actually attending to the signaller or physically unable to see them), from the overall average of gesture use; see text for details of calculations. White bars represent silent gestures, grey bars represent audible gestures, and black bars contact gestures. Post hoc GamesHowell tests were used to explore differences in the choice of silent, audible or contact gestures according to the attentional state of the target audience: $* P<0.0001$

For both silent and contact gestures, the modalities that had showed adjustment to audience's attentional state in the corpus as a whole, there was a significant effect for audience attentional state, but no difference in the use of gestures designated as PR or ST, or interactions between the gesture category and the audience's attentional state. For silent gestures (ANOVA $n=78, F=0.039, d f=$ $3,74, \quad P=0.843)$, attentional state was significant $(F=25.32, d f=1,77, P<0.0001)$, whereas gesture category was not $(F=0.053, d f=1,77, P=0.819)$. For contact gestures (ANOVA $n=78, F=0.062, d f=3,74$, $P=0.803$, data transformed to correct for positive skew), attentional state was significant $(F=36.57, d f=1,77$, $P<0.0001)$, whereas gesture category was not $(F=0.080, d f=1,77, P=0.778)$.

For audible gestures, where no adjustment for audience's attention was found overall, the data were still positively skewed following transformation, so non-parametric statistics were applied. In this case, the interaction between attentional state and gesture category was significant (Kruskal-Wallis test $\mathrm{chi}^{2}=13.82, d f=3, P=$ 0.003). Post hoc tests revealed that there was no significant adjustment to attentional state in ST gestures (MannWhitney $U=150.5, P=0.834$ ), but a significant increase in the use of PR audible gestures to attentive recipients (mean percentage variation from norm when recipient attending $=30.75$, mean percentage variation from norm when recipient not attending $=-30.24$, Mann-Whitney $U=108.5, P=0.0024)$. Critically for the ontogenetic ritualization hypothesis, this adjustment does not occur in the predicted direction: that is, audible gestures were not used to attract attention from inattentive recipients but were used more with an already-attentive audience. Indeed, if this prediction had been used to justify a one-tailed test, we would not have found a significant difference in the predicted direction. We suggest that the only reasonable explanation of this anomaly is the small sample size of potentially ritualized audible gestures available for analysis. In contrast to the 15 types of audible gesture classed as species-typical, only 3 audible gestures could be classed as potentially ritualized (Dangle, Object move and Tap object). Two of the three gestures (Dangle and Object move) have very strong visual components, and it could be argued that chimpanzees treat these as silent gestures, correctly employing them towards attentive recipients. However, we feel that the only appropriate conclusion is that this question remains untested in our data.

Do idiosyncratic gestures occur among the gestural repertoire of Sonso chimpanzees?

We found no evidence for any idiosyncratic gestures in wild chimpanzees. All of the 61 gestures recorded 3 or more times were used by more than one individual. Seven gestures were found in only one individual's repertoire; that is, each was recorded at least twice for those individuals. However, all those 7 gestures were recorded as used by other individuals on single occasions. Nor was there any evidence for 'matrisyncratic' gestures. Again, seven gestures formed part of the repertoires of only one matriline; but, again, all 7 were also used on single occasions by individuals outside of the matriline.

How frequently are gesture types used exclusively 'one-way' between dyads?

We examined the extent of 'one-way' usage (i.e. a gesture that was used in intentional communication by $\mathrm{A}$ to $\mathrm{B}$, but never by $\mathrm{B}$ to A) among the 5 individuals with the largest repertoires (4 of these individuals were also among the 5 individuals recorded as having received the most cases of gesture). A mean of $17.8 \% \pm 5.0$ (range 7-12 gestures) of these individuals' repertoires were one-way gestures: recorded as produced but not received by that individual. To set this finding into context, these individuals were recorded as producing $25.4 \% \pm 12.8$ more cases of gesture than they received (range 21-119 cases). This asymmetry stems from the fact that all were juveniles, and gestures made by juveniles to adults are often not reciprocated; the opposite would be found with adult females, which receive more gestures than they produce. 
Does the physical form of potentially ritualized gestures accord with ontogeny by ritualization from an effective action?

We examined two gestures, begging-reach and position, comparing their physical form with that of the effective actions (taking an object, and physically positioning, respectively) from which they might plausibly have been ritualized.

For the gesture begging-reach, we compared 68 taking actions with 163 begging-reach gestures: for the orientation of the palm, position of the fingers and which part of the hand was presented first (see Fig. 5). The 3 possible palm orientations differed significantly in frequency between the begging-reach gesture and the action of taking $(3 \times 2$ between-subjects ANOVA $F_{2,48}=16.90, P=0.01$ ). Specifically, comparing gesture and action for the 3 palm positions: the begging-reach gesture was usually performed with the palm held vertically (gesture: $n=12$ mean $=$ $45.5 \pm 26.0$; action: $n=6$ mean $=2.4 \pm 5.8$; planned $t$ test $t_{16}=3.96, P=0.001$ ), whereas the take action was usually performed with the palm held down (gesture: $n=12$ mean $=14.0 \pm 16.1$; action: $n=6$ mean $=62.9$ \pm 24.7 ; planned $t$ test $t_{16}=5.09, P=0.001$ ). There was no difference in the frequency with which the up position was used (gesture: $n=12$ mean $=38.4 \pm 25.6$; action: $n=6$ mean $=24.8 \pm 29.5 ;$ planned $t$ test $t_{16}=1.01, \quad P=$ $0.135)$. The use of the curled or extended finger position also differed significantly between begging-reach and take $\left(2 \times 2\right.$ between-subjects ANOVA $F_{1,32}=4.19, \quad P=$ 0.049). However, comparing gesture and action for the 2 finger positions, the difference in the frequency with which the fingers were held in an extended position only approached significance (gesture: $n=12$ mean $=46.1 \pm 30.5$; action: $n=6$ mean $=20.6 \pm 18.6$; planned $t$ test $t_{16}=$
1.87, $P=0.079$ ), and there was no difference in the frequency with which they were held in the curled position (gesture: $n=12$ mean $=51.8 \pm 32.8$; action: $n=6$ mean $=69.5 \pm 30.5$; planned $t$ test $t_{16}=1.10, P=$ $0.290)$. Finally, the part of the hand presented first did not differ between begging-reach and take $(2 \times 4$ betweensubjects Kruskal-Wallis $H=0.05 d f=1, P=0.826$ ), with the front of the fingers predominantly used in both the begging-reach gesture $(n=12$ mean $=84.6 \pm 20.3)$ and take actions $(n=6$ mean $=71.0 \pm 27.5)$.

For the gesture position, we compared 130 positioning actions with 127 position gestures, for the part of the hand used to perform the movement (see Fig. 6). The part of the hand used differed significantly between the position gesture and the positioning action $(2 \times 5$ between-subjects ANOVA $\left.F_{4,60}=12.22, \quad P<0.0001\right)$. Specifically, the palm was used significantly more often to perform the action rather than the gesture (gesture: $n=7$ mean $=$ $2.6 \pm 4.9$; action: $n=7$ mean $=49.5 \pm 18.7$; planned $t$ test $t_{12}=6.37, P<0.0001$ ), whereas the back of the fingers was used to perform the gesture rather than the action (gesture: $n=7$ mean $=24.1 \pm 19.2$; action: $n=7$ mean $=6.4 \pm 9.5$; planned $t$ test $\left.t_{12}=2.24, P=0.045\right)$. Although the front of the fingers was predominantly used to perform the gesture $(n=7$ mean $=62.8 \pm 26.8$ ), the difference in frequency with the action $(n=7$ mean $=$ $37.7 \pm 22.7$ ) only approached significance (planned $t$ test $\left.t_{12}=1.91, P=0.081\right)$. The knuckles and back of the hand were used rarely in either gestures $(n=7$, knuckles: mean $=3.5 \pm 5.9$; back of hand: mean $=6.2 \pm 9.6)$ or actions ( $n=7$ knuckles: mean $=5.4 \pm 9.2$; back of hand: mean $=1.1 \pm 2.9$ ), and there was no difference in the frequency with which either was used (knuckles: planned $t$ test $t_{12}=0.45, P=0.663$; back of hand: planned $t$ test $\left.t_{12}=1.35, P=0.202\right)$.
Fig. 5 Comparison of the physical form of Reach gesture with the corresponding action of taking. White bars represent reach gestures; black bars represent actions of taking; the $y$-axis shows percentage of gestures showing each physical feature. Planned $t$ tests were used to explore differences between the physical form of gesture and action: $* P<0.1$, $* * * P<0.001$

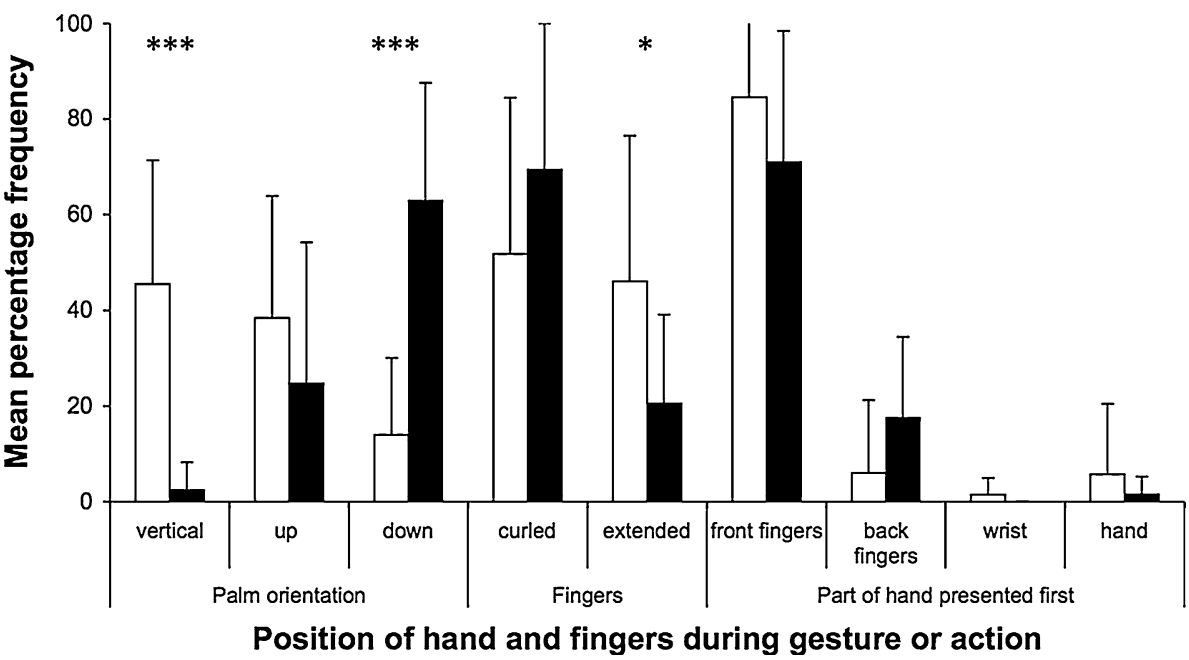




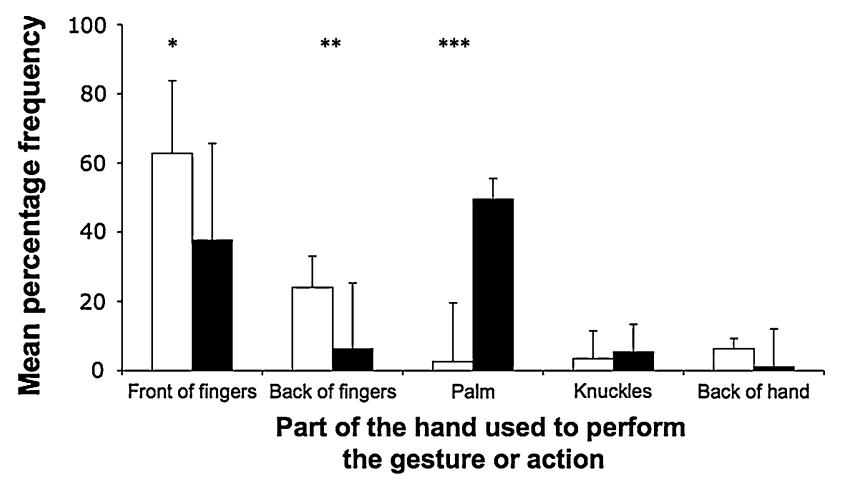

Fig. 6 Comparison of the physical form of Position gestures with the corresponding action of positioning. White bars represent position gestures; black bars represent actions of positioning. Planned $t$ tests were used to explore differences between the physical form of gesture and action: $* P<0.1, * * * P<0.001$

Does the gestural repertoire of Sonso chimpanzees match that at other sites?

Having found no evidence of idiosyncratic use, or of any functional difference between gestures that might plausibly have been ritualized and those that must be species-typical, we considered instead the possibility that the entire gestural repertoire was species-typical. And for chimpanzee gestures that are species-typical, it might be that they have a more ancient origin in the great ape lineage, so we also considered the possibility of 'family-typical' gestures, i.e. gestures that are species-typical in more than one great ape species.

We compared the repertoire of Sonso chimpanzee gesture types with that recorded in three other chimpanzee populations (using published studies of gesture at Gombe, Mahale and the captive Yerkes group, with additional data from a captive study at the Delta Regional Primate Center not focused on gesture in particular). Gorilla and orangutan repertoires were extracted from published studies of gesture (Table 1). In all cases, we excluded behaviour that did not fit our definition of gesture (e.g. static postures, such as crouching, treated as a gesture at Gombe; facial expressions, such as pout face, treated as a gesture at Yerkes; and effective actions, such as 'begging' with the mouth, treated as a gesture at Gombe and Yerkes). Repertoire overlap was examined in two ways: how many of gestures recorded in other chimpanzee studies (or great ape species) were recorded in the current study of one Ugandan chimpanzee community and how many of the Sonso chimpanzees' gestures have been recorded in other chimpanzee studies (or great ape species). In the case of the comparison with the gorilla repertoire, we used the finer detail specifications of gestures at Sonso (115), as the gorilla study used a similarly detailed level of categorization.

Most gestures, previously recorded in chimpanzees at other sites in Africa or in captivity, were also recorded at
Sonso in the present study (Gombe: $100 \%, 56$ out of 56 ; Mahale: $97 \%, 59$ out of 61; Yerkes, captive: $97 \%, 29$ out of 30 ). Moreover, a considerable number of gestures in the repertoire recorded for the gorilla and orangutan were also found in this study of Sonso chimpanzees (gorilla: 60\%, 72 out of 121 ; orangutan: $80 \%, 43$ out of 54 ). Twenty-four gestures were recorded from all three great ape genera.

Looking at the question from the other perspective, 47 of the 66 gestures recorded at Sonso have also been recorded as gestures in other chimpanzee gestural studies and a further 7 have been described in other chimpanzee studies where they were not treated as gestures. Further, of the remaining 12 Sonso gestures not recorded in other chimpanzee gesture studies, 10 have been recorded in other great ape species (9 in Gorilla, 1 in Pongo). Only two gestures (Object in mouth approach, Foot present) were uniquely noted at Sonso.

\section{Discussion}

In this study, we used a definition of 'gesture' that insisted upon evidence of intentionally communicative use for each instance analysed: potentially, therefore, we may have excluded from analysis many other communicative displays that function without involving intent to influence others. The restriction to intentional gesturing was based on evidence that gesturers were paying attention to their target audience before signalling, they waited for a response if it was not immediate, and they persisted in various ways if none or an inappropriate response was given. When we examined how a chimpanzee's choice of gesture varied according to the attentional state of its audience, we found further evidence of the intentional nature of chimpanzee gestural communication. When the audience was already attending to them, the signaller was significantly more likely to choose a silent gesture than when they could not be seen by the audience. Conversely, when the audience was not able to see the signaller, a contact gesture was significantly more likely to be used than when the audience was already attending. Consistent with many previous studies of great ape gesturing (see Introduction), Budongo chimpanzees use gestures in a flexible and goal-directed way.

There has been controversy, in recent literature, about the ontogeny of the intentional gestures of great apes. In one hypothesis, gesture use is constructed in dyadic interactions by a process of mutual conditioning, termed 'ontogenetic ritualization' (Tomasello and Call 2007). In this process, a social action by one participant that is originally mechanically effective comes to be anticipated by the other, so that the desired result is gained after only the start of the action sequence has been performed. That 
success, in turn, reinforces the early part of the action sequence or intention movements that precede it, such that they come to have the status of a gesture-for those two individuals, in that specific direction of communication, only. Although this hypothesis was able to account for the data reported in several studies, more recently doubts about it have arisen, as discussed in the Introduction. Particularly, Genty et al. (2009), comparing several gorilla populations, examined its specific predictions and found no clear support for the idea. Like Tomasello and colleagues, Genty et al. detected no evidence that their subjects had acquired gestures by imitation or other means of social transfer from conspecifics, such as population-specific differences in repertoire. They therefore proposed that perhaps all gorilla gestures are species-typical as a result of genetical channelling in development, as with communicative signals of most other animals-despite the unusually large sizes of repertoires and the undoubted fact of the gestures' intentional usage.

In the present study, we attempted a similar separation of potentially ritualized gestures from those where we could see no plausible origin in an effective action, for which we adopted the null hypothesis of a species-typical distribution as a result of genetical channelling in development. We, similarly, could find no characteristic differences between the resulting sets. For both, the choice of gesture was equally adjusted to the attentional state of the audience: silent gestures were used more for audiences who were attending, and contact gestures more for those who could not see the signaller. Both sets were used across a similarly wide range of contexts. Tomasello and Call (2007) discussed the case of intentional gestures whose form does not relate to intention movements (i.e. in the present study, all the gestures we classed as 'species-typical'). They suggested that these are attention getters: conspicuously noisy actions whose function in attracting attention results from ritualization, though their form does not. If so, then we should have found the greatest sensitivity to the audience's attention with audible gesturing, and with species-typical gestures in particular. We did not: in fact, species-typical audible gestures were the only ones where no significant adjustment to audience attentional state was found.

Given the evidence that species-typical gestures were employed in a fully flexible, intentional fashion, we reexamined the hypothesis that ontogenetic ritualization provides the major means by which great apes acquire their repertoire of intentional gestures. We made a close examination of two gestures, which would seem particularly clear candidates for ritualization from mechanically effective actions: begging-reach, apparently used to request a desired object (from the action of taking an object); and position, apparently used to gently signify a desired change in bodily position (from the action of physically moving the other). If they were indeed ritualized, we reasoned, their physical form should retain traces revealing their origins as physically effective actions. However, on several parameters we measured, the gestures differed systematically from the actions in how they were made: the specific part of the hand that was used, the orientation of the palm, whether fingers were curled or straight, etc. all differed between action and gesture. Of course, in other ways, these gestures and actions were more similar: they were, after all, originally picked out as having a potential developmental connection by the basic similarity of form. The characteristic differences between these gestures and the corresponding physically effective actions mean, however, that is not possible to describe these gestures as the intention movements or early phases of the corresponding effective actions. A possible source of support for the ritualization theory, therefore, was not confirmed.

Perhaps most tellingly of all, we found no evidence of idiosyncratic usage within the Sonso community of chimpanzees: all gestures were used by at least two individuals, although sometimes only at very low frequency. (Nor was there any sign of gesture use running in matrilines.) Although 'one-way' usage of gestures occurred, as would be expected on any hypothesized ontogeny, the frequency of asymmetric gesture use was not high, as might have been expected from ritualization within dyads.

We conclude that the hypothesis of ontogenetic ritualization, although entirely plausible as a learning process, is unnecessary to explain the origin of intentionally communicative gestures. Similarly, although there is evidence that chimpanzees can learn novel motor procedures by imitation (Hobaiter and Byrne 2010), we find no new evidence to change the conclusion of previous research (Call and Tomasello 2007b) that noimitation or any other form of observational learning from conspecifics is involved in the acquisition of gestures by chimpanzees. We therefore find no evidence that would lead us to discard the simplest hypothesis that the chimpanzee gestural repertoire is species-typical. Naturally communicative gestures of great apes may, in their ontogeny, be more similar to primate vocalizations than has been realized.

Although, for wild chimpanzees, this is the first comprehensive study made specifically of gesture, researchers at two Tanzanian populations (at Gombe and Mahale) have also described chimpanzee gestures. In the present study, the rate of adding new gestures to the Sonso repertoire appears close to asymptote, so it is not unreasonable to compare our findings to those of such long-term studies. There are inevitably slight variations between different projects in the level of 'splitting' and 'lumping' of behavioural categories, but using broadly similar criteria the repertoire sizes of these three chimpanzee populations 
are similar: Sonso 66 (this study; we also used a categorization, in which separations were clearly finer-grained those made at the other sites, giving 115 gestures), Gombe 61 (Goodall 1986; Plooij 1984), Mahale 69 (Nishida et al. 1999). In captivity, Tomasello and colleagues have studied the gestural communication of Yerkes chimpanzees and described a much smaller repertoire of 33 gestures (Tomasello et al. 1994, 1985, 1989). However, they added new gesture types in each successive paper, and further new examples were reported by other researchers working with the same group (Pollick and de Waal 2007), suggesting that the Yerkes repertoire has yet to reach asymptote. In our study, asymptote was only approached at the end of 2 years of fieldwork, involving 266 days observation. We therefore caution against the premature assumption that a gesture is absent from the repertoire after shorter study periods.

At Sonso, no individual's repertoire of gesture types was as large as the 66 recorded for the whole community: the largest was 41. However, we found that the size of an individual's repertoire was closely predicted by the amount of gesturing we had recorded for it, suggesting that most individual repertoires had yet to reach asymptote. When individuals were plotted on the same graph of the community repertoire over time, the majority fell closely on the cumulative curve for the group, supporting this suspicion. The repertoire recorded at different ages varied, with the greatest size found in the juvenile period, declining thereafter. However, here too, the repertoire size was closely predicted by the total amount of gesturing recorded: the biggest differences, then, may be less in repertoire sizes than in the sheer amount of gesture use that is seen in chimpanzees at different ages.

If, as we suppose, the repertoire of gestures used by chimpanzees is based on species-typical patterns, then not only should the repertoire size recorded in different populations be similar - as appears to be so, if the lower repertoire noted in captivity has yet to reach asymptote-but the specific gestures should also overlap. In some ways, this presents the sharpest difference from the hypothesis that ontogenetic ritualization is the 'major learning process' involved in gesture ontogeny (Tomasello and Call 2007 , p. 225), because in that hypothesis idiosyncrasy and variation should be the norm, or at least commonplace. Comparing the repertoire in detail with those noted in other chimpanzee studies, both in the wild and in captivity, we found a high level of commonality. Close to $100 \%$ of chimpanzee gestures recorded elsewhere in Africa or in captivity were also recorded at Sonso (including some described as "rare" or "idiosyncratic" in the studies that reported them): only 3 gestures described in other chimpanzee studies were not recorded at Sonso (one of which has been noted in the gorilla). Conversely, over $70 \%$ of Sonso gestures have also been recorded in other chimpanzee studies. This asymmetry suggests that the recorded repertoire of gestures at Sonso is actually somewhat larger, when analysed at the same level of detail, than that of many other studies. Since the Sonso repertoire is clearly an asymptotic estimate, we suggest that other gestures may yet be identified at those other sites, whereas identification of new gestures at Sonso is less likely. Consistent with this interpretation is the fact that no idiosyncratic gestures were found at Sonso, and the generality across individuals in the use of any particular gesture was predictable from its total frequency of occurrence in the corpus. The smaller repertoires and apparently idiosyncratic gestures described in captivity, we suggest, are likely to be artefacts of repertoires which have by no means reached asymptote, at which point most 'idiosyncratic' gestures would be seen to be part of the larger species repertoire.

In captivity, it is possible that apes acquire some of their gestures by imitation of human actions or by other human influence. The regular experience of unusual social and physical contexts, the lack of clear indicators of success and failure from the human-controlled environment, and the opportunity to regularly observe and interact with people may act to promote occasional acquisition of new gestures through imitation, in particular of human caretakers, or ontogenetic ritualization through regular interaction with them (e.g. the idiosyncratic 'disco arm shake', noted in a single gorilla by Genty et al., was only given to zoo staff). Human influences may be the source of the idiosyncrasy frequently reported in captive studies of ape gesture (though note the issue, discussed above, of the way in which 'idiosyncratic' has sometimes been defined), but intergroup comparisons show none of the differences between repertoires to be expected if imitation were an important means of gesture acquisition (chimpanzees, Call and Tomasello 2007b; gorillas, Genty et al. 2009). The high level of commonality reported in the present study, between gestures in different populations of wild chimpanzees, similarly argues against gestures as social traditions. We therefore find no reason to discard the more parsimonious species-typical hypothesis in favour of any more cognitively complex suggestions, such as social learning by imitation or ontogenetic ritualization within dyads.

When we came to compare the gestures used by Sonso chimpanzees with those identified in studies of the other two genera of non-human great ape, the level of overlap was remarkably high: Gorilla $60 \%$, Pongo $80 \%$. Instead of merely a species-typical repertoire, it seems that the great apes share an extensive family-typical repertoire of gestures: indeed, the same 24 gesture types were found in all of Pan, Gorilla and Pongo. Genty et al. (2009) describe a repertoire of 126 gorilla gestures, using a finer-grained 
definition. However, when we applied the same criteria to the Sonso data, the chimpanzee repertoire only reached 115 gestures. Moreover, unlike the Sonso chimpanzee repertoire, their gorilla repertoire was not shown to be at asymptote. Gorillas may, therefore, have the largest gestural repertoire of the great apes, and orangutans the smallest, but until a much wider range of local populations is included in the sample any such comparisons are probably premature. More importantly, it is clear that these repertoires are all large, and all are founded on considerable commonality of gesture across the whole family of great apes.

These conclusions leave us with two significant puzzles, which need to be addressed in subsequent research. Firstly, although great ape gestural communication islike the displays of most animals examined by ethologists-based on a species-typical repertoire, most simply explained as a result of genetical channelling, it remains the case that these gestures are used in a highly intentional manner. Might it therefore be that the degree of intentional signalling by other species has been systematically underestimated? Ristau's (1991) studies of the injury-feigning displays of the piping plover give a strong hint that this may be so. In the 'broken-wing' display, an adult runs along the ground trailing its wing as if broken, often successfully in luring a predator away from the nest. This display is given routinely under similar conditions by all members of injury-feigning plover species and indeed is widespread among the subfamily Charadriinae; it is therefore undoubtedly biologically given. But Ristau found that piping plovers adjusted their displays according to whether their goal of distraction was being met, specifically performing further displays within the visual field of the potential predator. The second puzzle is that, if great apes are capable of using an extensive system of gestures in an intentional and goal-directed way, why do they not augment this repertoire by learning new gestures-either to communicate in a more specific way or to deal with novel circumstances? It is not the case that great ape motor systems would be inadequate for the acquisition of complex, novel manual patterns: in the domain of food processing, the evidence is overwhelming that they can. Moreover, with human influence, great apes can acquire gestures that are certainly not part of their biologically given repertoire (e.g. the signs of American Sign Language: Gardner and Gardner 1969; Gardner et al. 1989). In the environments in which the ape species evolved, the biologically given set of gestures may well be adequate for all normal purposes, so that any ability to augment the repertoire would not be demonstrated. But in captivity, too, it appears that the semblance of gestural innovation is largely illusory or an artefact of human influence; so could it be that the apes simply do not appreciate the potential of symbolic referential communication?

Acknowledgments We thank all the staff of the Budongo Conservation Field Station, especially Amati Stephen, and thank the BCFS project's founder Vernon Reynolds and its current scientific director Klaus Zuberbühler for allowing us to work at the site and to use data from the project records. For permission to work in Uganda, we thank the Uganda National Council for Science and Technology, the Presidents Office, the Uganda Wildlife Authority and the Uganda Forest Authority. Fieldwork of $\mathrm{CH}$ was generously supported by grants from the Wenner-Gren Foundation (http://wennergren.org) and the Russell Trust. The thoughtful comments of three anonymous referees were useful in improving the clarity of our theory and writing.

\section{References}

Altmann J (1974) Observational study of behaviour: sampling methods. Behaviour 49:227-265

Armstrong DF, Wilcox S (2007) The gestural origin of language. Oxford University Press, Oxford

Arnold K, Zuberbuhler K (2006) Semantic combinations in primate calls. Nature 441:303

Arnold K, Zuberbuhler K (2008) Meaningful call combinations in a non-human primate. Curr Biol 18:R202-R203

Call J, Tomasello M (2007a) The gestural communication of apes and monkeys. Lawrence Erlbaum Associates, Hillsdale

Call J, Tomasello M (2007b) The gestural repertoire of chimpanzees (Pan troglodytes). In: Call J, Tomasello M (eds) The gestural communication of apes and monkeys. Lawrence Erlbaum Associates, Mahwah, pp 17-39

Cartmill EA, Byrne RW (2007) Orangutans modify their gestural signalling according to their audience's comprehension. Curr Biol 17:1345-1348

Cartmill EA, Byrne RW (2010) Semantics of primate gestures: intentional meanings of orangutan gestures. Anim Cogn 13:793804

Cheney DL, Seyfarth RM (1985) Vervet monkey alarm calls: manipulation through shared information? Behaviour 94:150166

Cheney DL, Seyfarth RM (1990a) Attending to behaviour versus attending to knowledge: examining monkeys' attribution of mental states. Anim Behav 40:742-753

Cheney DL, Seyfarth RM (1990b) How monkeys see the world: inside the mind of another species. University of Chicago Press, Chicago

Cheney DL, Seyfarth RM (1996) Function and intention in the calls of non-human primates. Proc Br Acad 88:59-76

Corballis MC (2010) The gestural origins of language. Wiley Interdiscip Rev Cogn Sci 1:2-7

Eggeling WJ (1947) Observations on the ecology of the Budongo Rain Forest, Uganda. J Ecol 34:20-87

Fouts RS, Fouts DH, Van Cantford TE (1989) The infant Loulis learns signs from cross-fostered chimpanzees. In: Gardner RA, Gardner BT, Van Cantford TE (eds) Teaching sign language to chimpanzees. State University of New York Press, New York, pp 280-292

Gardner RA, Gardner BT (1969) Teaching sign language to a chimpanzee. Science 165:664-672

Gardner RA, Gardner BT, Van Cantfort TE (1989) Teaching sign language to chimpanzees. SUNY Press, New York

Genty E, Byrne RW (2010) Why do gorillas make sequences of gestures? Anim Cogn 13:287-301 
Genty E, Breuer T, Hobaiter C, Byrne RW (2009) Gestural communication of the gorilla (Gorilla gorilla): repertoire, intentionality and possible origins. Anim Cogn 12:527-546

Goodall J (1968) The behaviour of free-living chimpanzees of the Gombe Stream Reserve. Anim Behav Monogr 1:161-311

Goodall J (1986) The chimpanzees of Gombe: patterns of behavior. Harvard University Press, Cambridge

Hauser MD, Chomsky N, Fitch WT (2002) The faculty of language: what is it, who has it, and how did it evolve? Science 298:1569-1579

Hewes GW (1973) Primate communication and the gestural origins of language. Curr Anthropol 14:5-24

Hobaiter C, Byrne RW (2010) Able-bodied wild chimpanzees imitate a motor procedure used by a disabled individual to overcome handicap. PLoS One 5:e11959

Janik VM, Slater PJB (1997) Vocal learning in mammals. Adv Study Behav 26:59-99

Janik VM, Slater PJB (2003) Traditions in mammalian and avian vocal communication. In: Fragaszy DM, Perry S (eds) The biology of traditions: models and evidence. Cambridge University Press, Cambridge, pp 213-235

Laporte MNC, Zuberbuhler K (2010) Vocal greeting behaviour in wild chimpanzee females. Anim Behav 80:467-473

Leavens DA, Hopkins WD (1998) Intentional communication by chimpanzees: a cross-sectional study of the use of referential gestures. Dev Psychol 34:813-822

Leavens DA, Russell JL, Hopkins WD (2005) Intentionality as measured in the persistence and elaboration of communication by chimpanzees (Pan troglodytes). Child Dev 76:291-306

Liebal K, Call J, Tomasello M (2004a) The use of gesture sequences in chimpanzees. Am J Primatol 64:377-396

Liebal K, Pika S, Call J, Tomasello M (2004b) To move or not to move; how apes adjust to the attentional state of others. Interact Stud 5:199-219

Liebal K, Pika S, Tomasello M (2006) Gestural communication of orangutans (Pongo pygmaeus). Gesture 6:1-38

Miles HL (1986) Cognitive development in a signing orangutan. Primate Rep 14:179-180

Nishida T, Kano T, Goodall J, McGrew WC, Nakamura M (1999) Ethogram and ethnography of Mahale chimpanzees. Anthropol Sci 107:141-188

Patterson F, Linden E (1981) The education of Koko. Holt, Rinehart, and Linden, New York

Pika S, Liebal K, Tomasello M (2003) Gestural communication in young gorillas (Gorilla gorilla): gestural repertoire, learning, and use. Am J Primatol 60:95-111

Plooij F (1979) How wild chimpanzee babies trigger the onset of mother-infant play and what the mother makes of it. In: Bullowa $M$ (ed) Before speech: the beginnings of interpersonal communication. Cambridge University Press, Cambridge, pp 223-243

Plooij FX (1984) The behavioral development of free-living chimpanzee babies and infants. Ablex Publishing Corporation, Norwood

Pollick AS, de Waal FBM (2007) Ape gestures and language evolution. Proc Natl Acad Sci 104:8184-8189
Rendall D, Owren MJ, Ryan MJ (2009) What do animal signals mean? Anim Behav 78:233-240

Reynolds V (2005) The chimpanzees of the Budongo Forest. Oxford University Press, Oxford

Ristau C (1991) Aspects of the cognitive ethology of an injuryfeigning bird, the piping plover. In: Ristau $C$ (ed) Cognitive ethology: the minds of other animals. Lawrence Erlbaum Associates, Hillsdale, pp 91-126

Rizzolatti G, Arbib MA (1998) Language within our grasp. Trends Neurosci 21:188-194

Seyfarth RM, Cheney DL (1986) Vocal development in vervet monkeys. Anim Behav 34:1640-1658

Seyfarth RM, Cheney DL, Marler P (1980) Vervet monkey alarm calls: semantic communication in a free-ranging primate. Anim Behav 28:1070-1094

Seyfarth RM, Cheney DL, Bergman TJ (2005) Primate social cognition and the origins of language. Trends Cogn Sci 9:264-266

Snowdon CT (1990) Language capacities of nonhuman animals. Yearb Phys Anthropol 33:215-243

Taglialatela JP, Savage-Rumbaugh S, Baker LA (2003) Vocal production by a language-competent Pan paniscus. Int $\mathrm{J}$ Primatol 24:1-17

Tanner JE, Byrne RW (1996) Representation of action through iconic gesture in a captive lowland gorilla. Curr Anthropol 37:162-173

Tanner JE, Byrne RW (1999) The development of spontaneous gestural communication in a group of zoo-living lowland gorillas. In: Parker ST, Mitchell RW, Miles HL (eds) The mentalities of gorillas and orangutans. Comparative perspectives. Cambridge University Press, Cambridge, pp 211-239

Tomasello M (1990) Cultural transmission in the tool use and communicatory signaling of chimpanzees? In: Parker ST, Gibson KR (eds) "Language" and intelligence in monkeys and apes. Cambridge University Press, Cambridge, pp 274-311

Tomasello M, Call J (2007) Intentional communication in nonhuman primates. In: Call J, Tomasello $\mathrm{M}$ (eds) The gestural communication of apes and monkeys. Lawrence Erlbaum Associates, Mahwah, pp 1-15

Tomasello M, George B, Kruger A, Farrar J, Evans E (1985) The development of gestural communication in young chimpanzees. J Hum Evol 14:175-186

Tomasello M, Gust D, Frost TA (1989) A longitudinal investigation of gestural communication in young chimpanzees. Primates 30:35-50

Tomasello M, Call J, Nagell C, Olguin R, Carpenter M (1994) The learning and use of gestural signals by young chimpanzees: a trans-generational study. Primates 35:137-154

Tutin CEG, McGrew WC (1973) Chimpanzee copulatory behavior. Folia Primatol 19:237-256

Vauclair J (2004) Lateralization of communicative signals in nonhuman primates and the hypothesis of the gestural origin of language. Interact Stud 5:365-386

Zuberbuhler K (2002) A syntactic rule in forest monkey communication. Anim Behav 63:293-299

Zuberbuhler K, Cheney D, Seyfarth R (1999) Conceptual semantics in a nonhuman primate. J Comp Psychol 113:33-42 